\title{
ARTIGO
}

dO https://doi.org/10.22481/praxisedu.v15i34.5507

\section{ORIENTAR-SE NOS HORIZONTES EPISTEMOLÓGICOS DA EXPERIÊNCIA: PROBLEMATIZAÇÃO E ETOPOIESE EM MICHEL}

FABRE

\author{
ORIENTATE YOURSELF ON THE EPISTEMOLOGICAL HORIZONS OF THE
}

EXPERIENCE: PROBLEMATIZATION AND ETHOPOIESIS IN MICHEL FABRE

\section{ORIENTARSE EN LOS HORIZONTES EPISTEMOLÓGICOS DE LA EXPERIENCIA: PROBLEMATIZACIÓN Y ETHOPOIESIS EN MICHEL FABRE}

\author{
Ibrahim Camilo Ede Campos \\ Universidade Federal de Alagoas - Brasil \\ Walter Matias Lima \\ Universidade Federal de Alagoas - Brasil
}

\begin{abstract}
Resumo: Este artigo apresenta a pedagogia do problema em Michel Fabre, modelo de normatividade educacional centrado na experiência. A problematização dessa experiência articula dois instrumentos de orientação, metaforicamente representados na bússola e no mapa, como tentativa de a educação responder aos desafios de um mundo problemático. O mapa representa o construto histórico-cultural, os saberes construídos pela humanidade. A bússola representa a abertura e a polarização do espaço cognitivo na organização da experiência. A educação assume o papel de fornecer ao aluno esses dois instrumentos, auxiliando-o na busca e construção de seu próprio caminho considerando uma razão educativa prudencial e não injuntiva.
\end{abstract}

Palavras-chave: Filosofia da educação. Pedagogia e educação. Sistemas pedagógicos.

\begin{abstract}
This paper presents the pedagogy of the problem in Michel Fabre, educational normativity model centered on experience. The problematization of this experience connects two guidance tools, metaphorically represented in the compass and the map, as an attempt for education to meet the challenges of a troubled world. The map represents the historical and cultural construct, the knowledge built by humanity. The compass represents the openness and polarization of cognitive scope in the experience organization. Education plays the role of providing the students with these two tools, helping them to seek and build their own path from a prudential and non-injunctive educational reason.
\end{abstract}

Keywords: Philosophy of Education. Pedagogy and education. Pedagogical systems. 
Resumen: Este artículo aborda la pedagogía del problema en Michel Fabre, modelo de normatividad educativa centrado en la experiencia. La problematización de esta experiencia conecta dos instrumentos de orientación, representados metafóricamente en la brújula y en el mapa, con el propósito de que la educación enfrenta los desafíos de un mundo con problemas. El mapa representa el constructo histórico-cultural, los saberes construidos por la humanidad. La brújula representa la apertura y la polarización del ámbito cognitivo en la organización de la experiencia. La educación desempeña el papel de proporcionar al alumno estos dos instrumentos, ayudándolo en la búsqueda y construcción de su propio caminho, teniendo en cuenta una razón educativa prudencial y no injuntiva.

Palabras clave: Filosofía de la Educación. Pedagogía y educación. Sistemas pedagógicos.

\section{Introdução}

Filosofar sobre um objeto determinado e delimitado como a Educação implica buscar compreender o fundamento maior às práticas que dela resultam.

Aspiração à globalidade ou à unidade do saber, questionamento de respostas (e do próprio questionamento), descomprometimento com o imediatismo e imersão nas obras do passado para reconstituir problemas e apontar possíveis caminhos são notas distintivas dessa prática reflexiva (COMTE-SPONVILLE, 2002).

A filosofia, ademais, não visa a acumular ou a produzir saberes (tal o objetivo das ciências) (MEYER, 2010, p. 10), mas a refletir sobre esses saberes (COMTE-SPONVILLE, 2012), buscando explicações de maior abrangência, com sentido global em face das particularidades de cada fenômeno, pena de elas ficarem sem referências, desbussoladas.

Nessa medida, a filosofia da educação, como a define Reboul (2016, p. 3), é “antes de tudo uma interrogação, não um corpo de saberes, mas um questionamento de tudo o que nós sabemos ou cremos saber sobre a educação”, um questionamento radical (essencial) e vital, já que distanciado da estrita especulação teórica, ou seja, também afetado à prática, conforme se evidencia na literatura (OZMON; CRAVER, 2004; LUCKESI, 2011). Afinal, filosofar é pensar a vida e viver o pensamento (COMTE-SPONVILLE, 2006).

Sem um ethos único, sem transcendências nem referências morais unívocas e absolutas, em um ambiente de intensas e rápidas mudanças em diferentes sistemas que permeiam a vida social (tecnológico, político, educacional, jurídico, econômico, familiar, cultural...), as certezas que regiam as sociedades tradicionais cedem lugar à problematicidade. E mesmo as respostas emersas das ciências logo se transformam em questões (MEYER, 2010). 
Deflui dessa contemporaneidade uma ausência de obviedades, de certezas, somandose a isso, nessa perspectiva, o fato de não haver, em um primeiro momento, nem mesmo uma ordem ou critério seguro capaz de legitimar determinada orientação em detrimento de outra (FABRE, 2011a).

Um mundo problemático (ou pós-moderno) pressupõe falta de estabilidade, obstando respostas monolíticas, a sugerir, sim, referências, orientações (FABRE, 2011). "Viver e educar sem absoluto", tal é a metonímia que o título de artigo de Michel Fabre expressa em sua obra de conjunto (FABRE, 2016).

Como teorizar essa problematicidade no campo da educação? Objetiva-se apresentar algumas linhas do pensamento de Michel Fabre, articuladas no âmbito de uma pedagogia do problema, que dialoga fecundamente com epistemologias de autores como John Dewey (1859-1952), Gaston Bachelard (1884-1962), Gilles Deleuze (1925-1995) e Michel Meyer (1950-).

Fabre adstringe-se a uma concepção de normatividade educativa centrada na experiência, em que dois instrumentos geográficos, a bússola e o mapa, são metaforicamente explorados como tentativas de a educação responder aos desafios de um mundo problemático.

\section{Problematização da experiência e normatividade educacional}

À guisa de enquadramento epistemológico da teoria de Fabre, podem ser apontados três esquemas de legitimação na educação: "imitar, seguir a natureza e avaliar a experiência". (FABRE, 2011a, p. 57). O primeiro reflete um ethos estatizante dos valores, daí o tempo conservá-los, daí o ensino promovê-los, mimetizando o passado (FABRE, 2011a).

O segundo esquema de legitimação, ganhando frente no tempo em relação ao primeiro, é o de seguir a natureza, exemplificado por Rousseau em Emílio (1762) (FABRE, 2011a).

O terceiro é centrado na história, como alternativa concreta à contemporaneidade, centrada na filosofia da experiência (FABRE, 2011a), distanciado, de igual modo, das correntes pedagógicas clássica e tecnicista.

A corrente pedagógica clássica privilegia o conteúdo em detrimento do modo de transmitir esse conteúdo, submetendo o desejo de aprender à necessidade de aprender, mediante transmissão dos saberes acumulados (REBOUL, 2016). A segunda corrente, funcional ou tecnicista (instrumental), privilegia a exatidão, o controle rigoroso e a eficácia 
dos resultados. Centra-se nos objetivos-meios, nos objetivos-fins e no controle dos resultados na educação. Nesse sentido, sobrepõe-se a mensurabilidade, o controle, a previsibilidade articulada em forte encadeamento operacional - ao qualitativo, à liberdade, à indeterminabilidade exata dos resultados (REBOUL, 2016). Em uma palavra: sobrepõe a tecnicidade à eticidade.

A terceira corrente, inovadora, parte das experiências e vontades da criança, buscando adaptar o conteúdo a ser ensinado aos educandos. Eleva o desejo de aprender, enaltece a espontaneidade, o potencial da criatividade e decresce o valor da impositividade no ensino desses saberes (REBOUL, 2016), do enfoque sobre respostas a questões que não foram geradas pelos educandos.

Sob o vértice epistemológico dessa terceira corrente, a Educação tem de considerar a subjetividade e a singularidade do educando, renunciando a pretensões científicas de controle, previsão e quantificação (GALLO, 2004), qual seja, a uma massificação do ensino tendente à redução da realização das potencialidades do ser humano como agente e interagente na sociedade.

Ao invés de promover uma teleologia puramente determinista, voltada à transmissão de saberes definidos, a priori, pela cultura científica, a Educação deve, pois, estimular a integralização da experiência que se constitui em três dimensões.

$\mathrm{Na}$ dimensão das faculdades, ela é apresentada como cognição, imaginação e sensibilidade. Na dimensão ética, como autorreflexão e relação autêntica com o outro. Por sua vez, a dimensão temporal é compreendida como espontaneidade e inexauriência (SILVA, 2001), pois a transformação do sujeito, tendo-a como referência, possibilita novas experiências.

É tendo como referência a regulação ou organização da experiência, topos privilegiado no pensamento de Fabre, que se vai encaminhar uma normatividade educacional não injuntiva, prudencial, em que a retórica, ou seja, a negociação das distâncias ou diferenças entre os indivíduos (MEYER, 2011), prevalece sobre a submissão do discente ao docente, conferindo-se maior importância ao primeiro no sentido de se promoverem relações menos assimétricas (FABRE, 2011b).

Consoante o supraexposto, se não há direção única e segura a ser apontada, cabe à educação, diante desse mundo problemático, não direcionar o aluno, mas lhe fornecer instrumentos de referência (FABRE, 2011a), metaforizados na bússola e no mapa, para que ele, por si próprio, escolha e siga seu caminho (FABRE, 2011b). 
Como se organiza essa experiência? Fabre remonta ao pensamento de Dewey, para quem essa experiência não deve ser organizada unicamente de modo exógeno; devem ser valorizados a subjetividade, os projetos e problemas do sujeito (FABRE, 2011a) e, a esse respeito, não há transponibilidade na relação entre docente e discente.

Não se há, por outro lado, de organizar a experiência somente de modo endógeno (FABRE, 2011a), já que compreender o sentido alterístico da vida não é dispensável ao autoconhecimento. A rigor, poder-se-ia mesmo perguntar se seria possível uma separação do sujeito da respectiva morada - sentido etimológico de ethos - não significando, todavia, uma redução da parte ao todo, do individual ao coletivo.

Dewey propõe que essa experiência deva ser modulada por programas escolares que sejam concebidos não em si, mas como elemento referencial, objetivo, à semelhança de um mapa, na construção da subjetividade (DEWEY, 2004, p. 72 apud FABRE, 2011a, 67-68).

E o que vale a pena ser problematizado na educação? Nesse âmbito, Reboul (2016) guarda fortes semelhanças com o pensamento de Dewey. O que vale a pena ser ensinado no âmbito dos saberes escolares - experienciado, poder-se-ia dizer - é, no aspecto social, aquilo que une, que integra, a longo termo, a pessoa a uma comunidade que seja tanto maior quanto possível.

O que vale também ser ensinado é, no aspecto individual, o que libera, ou seja, é o que: a) aprendido, pode ser transferido para outras situações de vida, balizando futuras experiências; b) faz agir com base nesse ensino, desprendendo-se daquilo que o tolhe (REBOUL, 2016).

O terceiro critério é a alegria de se aprender, o que une o valor do rigor (a exigir um juízo de adequação, proporção e autocrítica) ao valor da graça, do descentramento do cálculo, do sentimento de satisfação espiritual de se ter aprendido um saber e de acrescer a si mesmo (REBOUL, 2016), como enaltecimento da plasticidade de ser e de agir .

\section{O losango da problematização: as funções de bússola e de mapa}

A organização da experiência em um mundo problemático é representada metaforicamente pelo "losango da problematização" (FABRE, 2011a, p. 68), onde se articulam a função de bússola e a função de mapa, instrumentos que possibilitam a orientação do aluno nesse mundo problemático. 
Afinal, o que é problematizar, quais suas características e obstáculos? E como se articulam as duas funções no referido losango? Há entre elas uma relação de dispensabilidade recíproca ou de precedência? Ou se trata de uma relação de complementaridade inafastável e fulcral para prover o aluno da instrumentação necessária?

Importa, em primeiro lugar, conceituar problematização, caracterizá-la e apontar seus principais obstáculos.

Problematizar é "desenvolver um questionamento buscando identificar os dados e as condições do problema e colocá-los em tensões" (FABRE; MUSQUET, 2009, p. 113). Os dados e as condições concernem ao posicionamento e à construção do problema. Os primeiros, apresentados pelo aluno ou professor, no início ou ao longo do processo, constituem escolhas, de acordo com a pertinência ou com as condições. São proposições de fato objetivas, que constringem, como a área, cor ou volume de um objeto (FABRE; MUSQUET, 2009).

Por sua vez, as condições, aduzem os referidos autores, "concernem aos critérios, aos princípios, aos conceitos que comandam o processo de problematização. São necessidades que devem ser levadas absolutamente em conta na construção e na resolução do problema" (FABRE; MUSQUET, 2009, p. 113).

Da articulação dos dados e das condições, surgem hipóteses de soluções a serem validadas ou infirmadas posteriormente (FABRE; MUSQUET, 2009).

Quatro características do processo de problematização podem ser elencadas. Trata-se de um processo multidimensional, ou seja, de posição, construção e resolução de problemas, sem haver entre elas uma única ordem sequencial, nada impedindo, por exemplo, a reformulação de problemas, revisitando dados e condições (FABRE; MUSQUET, 2009).

Como aponta Houssaye (2005), na problematização, as estruturas desse processo não são definidas a priori, mas construídas. O problema é construído, articulado com os dados e as condições, sendo os pontos de partida abertos à discussão e à revisitação, a fim de se testarem as hipóteses de solução. Não se trata, pois, de uma enunciação formal e descontextualizada de um problema trazido pelo sujeito educativo para que o aluno apenas o resolva.

Em relação à segunda característica, no referido processo, há uma dialética entre o conhecido e o desconhecido. A problematização pressupõe pontos de referência provisórios. Ademais, esse modelo de organização da experiência é informado por critérios normativos 
(morais, técnicos, jurídicos...), já construídos ou por serem construídos, que delineiam ou enquadram a problematização.

Por fim, há, nele, uma “esquematização funcional do real” (FABRE; MUSQUET, 2009, p. 113), sem pretensão de reproduzi-lo em inteireza, buscando-se, antes, construir ferramentas nesse processo (FABRE, 2009).

Um dos obstáculos à problematização consiste no escamoteamento da dimensão positiva, que consiste na investigação, na reflexão e na abertura daquilo que as respostas fecham e dão por resolvido. O segundo obstáculo consiste no escamoteamento do próprio problema, recorrendo-se, apressadamente, a soluções fáceis, amiúde, de frágil sustentação. Pode-se, ainda, obstaculizar a problematização por meio da assimilação do espaço-problema (o losango) e sua polarização a uma totalidade do real que não se pretende cobrir, sem discernir os dados e as condições do problema (FABRE, 2011a).

Estes obstáculos guardam estrita relação com a reificação dos saberes. Desde o início da história da filosofia, a resposta oculta a questão, que, no entanto, é sua razão de ser (MEYER, 2010), parecendo a primeira ter valor em si mesma (FABRE, 2007).

O esquecimento do problema que engendrou a resposta traz a ilusão de que ela se revela sem mediação do problema, como se fosse sempre evidente, exemplifica Fabre, que a Terra gira em torno do sol, sem desvelar a polêmica discussão científica, cultural, política e religiosa ínsita do tempo do Renascimento (FABRE, 2007, p. 72).

Os saberes como respostas, sem que sua gênese, as perguntas, se revele na sua inteireza, ensejam uma modalidade de reificação dessas respostas, dos resultados, vale dizer, uma descontextualização do questionamento que a engendrou (FABRE, 2011b), ou ainda uma separação dessas respostas do tronco vital do qual elas se serviram, ensinando-se os saberes sem problemas, petrificados, como se fossem evidentes, impondo-se neutralmente diante do alunado, ou seja, uma factualidade pura, desprovida da fonte que gerou essa resposta, qual seja, o problema (FABRE, 2012).

Entre a gênese do saber e a sua aplicação prática - contextos de problematicidade -, a escola, por não estar em nenhum desses dois loci, captura esse saber no estágio intermediário entre dois processos de catálise, parecendo esse saber subsistir em si, neutro, mantido, porém descontextualizado por meio de um enrijecimento conceitual a ponto de se coisificar em fatos inquestionáveis, desvinculando-o da empiria da qual ganhou vida (FABRE, 2007). 
Aponta-se, assim, a necessidade de se contemplarem três dimensões pedagógicas do problema: a) gênese histórica, b) corporificação teórica e c) abertura a novos problemas (FABRE, 2007).

\section{A bússola como metáfora da polarização do espaço cognitivo da problematização}

$\mathrm{Na}$ organização do processo de problematização, dois instrumentos geográficos são metaforicamente utilizados na epistemologia fabreana. A bússola, como metáfora do espaço cognitivo da problematização, representa a "abertura e a polarização de um espaço cognitivo" (FABRE, 2011a, p. 69) em condição, dados, problema e solução. É o “processo de problematização que abre seus próprios pontos cardeais" (FABRE, 2011b, p. 108).

Ainda nas palavras do citado autor, ela "não dita a direção, ela apenas polariza o espaço para que o viajante possa determinar sua rota. $\mathrm{O}$ uso da bússola se impõe em um espaço fluido para o qual todas as direções se equivalem" (FABRE, 2011a, p. 63). Vale dizer que a bússola não aponta qual caminho seguir, apenas possibilita orientações.

No losango da problematização, cada extremidade dos pontos cardeais toca internamente as extremidades desse quadrilátero: o oeste (problema), o leste (a solução), o norte (as condições) e o sul (os dados) (Figura 1).

Figura 1 - Losango da problematização

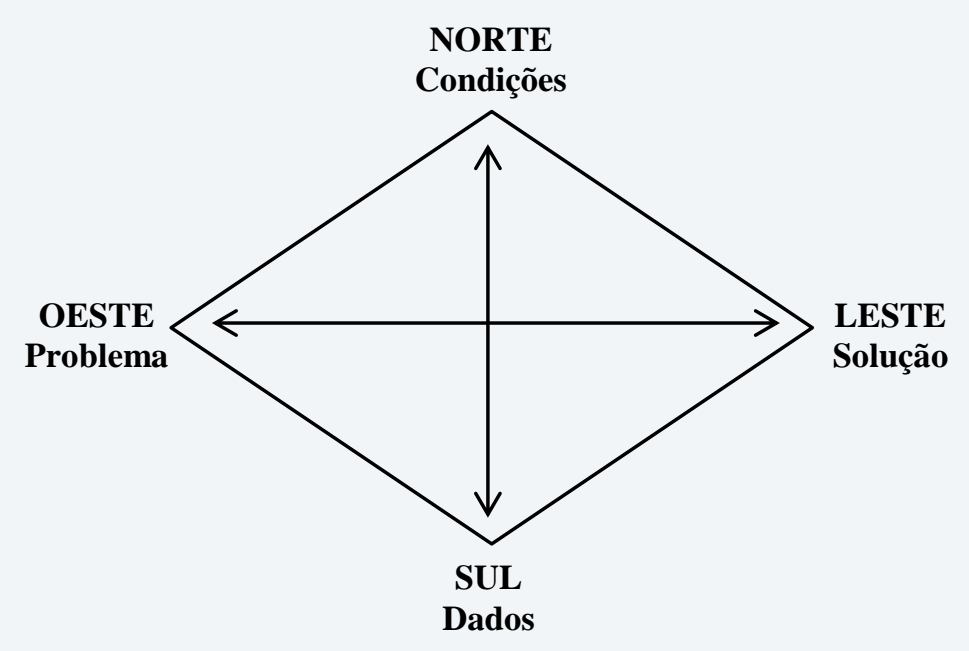

Fonte: Fabre (2011a, p. 69).

Fabre exemplifica tal representação na obra "A volta do mundo em 80 dias", de Júlio Verne (1828-1905): o problema de dar a volta ao mundo em 80 dias, a solução dos itinerários 
possíveis, a condição da continuidade espaço-temporal, os dados das redes e horários (FABRE, 2011a).

A indução da problematização junto ao aluno, ou seja, da estruturação do espaço cognitivo em problemas, condições, dados e soluções consequentes (FABRE; MUSQUER, 2009, p. 112-113), bem assim a catálise dessa problematização por meio de elementos que intensifiquem, sob o aspecto emotivo, o processo educativo estruturante da experiência (FABRE, 2011a), são exemplificadas por Fabre através da obra Emílio, de Rousseau, em várias passagens. Em uma delas, Jean-Jacques, ao perceber o desinteresse de Emílio pelas lições teóricas sobre astronomia, adota outro método:

No dia seguinte pela manhã eu lhe proponho um passeio antes do almoço; não quer outra coisa; as crianças estão sempre dispostas a correr e esta tem boas pernas. Subimos à floresta, percorremos os Champeaux, perdemo-nos, não sabemos mais onde nos encontramos; e quando se trata de voltar não conseguimos encontrar nosso caminho. O tempo passa, vem o calor, temos fome; apressamo-nos, erramos em vão de um lado e de outro, por toda parte não deparamos senão com bosques, pedreiras, planícies, nenhuma informação nos permite reconhecermos o caminho. Cansados, esgotados, esfomeados, com nossas corridas não fazemos senão nos perdermos mais. Sentamo-nos enfim para descansar, para deliberar. Emílio, que suponho educado como outra criança, não delibera, chora. Não sabe que estamos às portas de Montmorency, e que um simples bosque no-las esconde; mas esse bosque é uma floresta para ele, um homem de sua estatura se enterra entre arbustos.

\section{JEAN-JACQUES}

(...) Se pudéssemos, da floresta, observar a posição de Montmorency!...

EMÍLIO

É, mas ontem nós víamos a floresta e daqui não vemos a cidade.

\section{JEAN-JACQUES}

É o problema... Se pudéssemos não nos incomodar com ela para encontrar sua posição!...

\section{EMÍLIO}

Meu pobre amigo!

JEAN-JACQUES

Não dizíamos que a floresta se achava...

\section{EMÍLIO}

Ao norte de Montmorency.

\section{JEAN-JACQUES}

Por conseguinte, Montmorency deve estar...

\section{EMÍLIO}

Ao sul da floresta.

JEAN-JACQUES

E teremos algum meio de encontrar a direção a meio-dia?

\section{EMÍLIO}

Sim, pela direção da sombra.

JEAN-JACQUES

Mas o sul? 


\section{EMÍLIO}

Que fazer?

JEAN-JACQUES

O sul opõe-se ao norte.

EMÍLIO

É verdade; basta então procurar o lado oposto à sombra. Ah! eis o sul, eis o sul, por certo Montmorency é deste lado.

\section{JEAN-JACQUES}

Podeis ter razão; sigamos este atalho através da floresta.

EMÍLIO, batendo palmas e dando um grito de alegria.

Estou vendo Montmorency! Aí na frente de nós, bem visível. Vamos almoçar, vamos depressa; a astronomia serve para alguma coisa (ROUSSEAU, 1979, 145-147).

Os dados, quais sejam, a informação dita por Jean-Jacques, na noite anterior, de que a floresta estava ao norte de Montmorency, articulam-se com as condições de polarização geográfica norte-sul, a fim de testar as hipóteses de solução para o problema de encontrar o caminho de casa (FABRE, 2011a).

\section{O mapa como representação do construto histórico-cultural no processo de problematização}

Uma bússola sem mapa, sem representação do território por onde se vai percorrer, não tem relevância. O mapa representa o construto histórico-cultural no processo de problematização, metaforiza a descrição das experiências passadas, as trilhas já percorridas pela humanidade (individualmente, pelo educador) ao longo de sua história, os percalços, as sinuosidades, a claridade ou a obscuridade dos caminhos, servindo como pontos de referência (FABRE, 2011a).

O mapa representa, pois, o que já se construiu no passado, os saberes desvelados na senda histórica, os caminhos já percorridos e explorados em maior ou menor medida, vale asseverar, os saberes construídos nos costumes, na família, no direito, nas ciências, na arte, nas culturas em sentido amplo.

Oferece o mapa, portanto, ainda que parcialmente, os dados e as condições do problema, este, insiste-se, como algo individual (FABRE, 2011a). Deveras, a problematização pressupõe esse legado cultural para não funcionar no vazio (FABRE, 2011a).

Articulando referências, cabe ainda citar Fabre:

[...] se extrapolamos a questão da orientação e da condução da experiência, a problematização exige uma diferenciação subjetiva (é o meu projeto, meu 
problema), uma função de ancoragem (localização), uma função referencial (esquematização do real). O mapa é a ferramenta que articula todos esses balizamentos (FABRE, 2011b, p. 110).

A experiência singular não é ditada pelo mapa, que apenas representa o complexo cultural, os percursos já trilhados pela humanidade, permitindo ao aluno "inscrever sua problemática subjetiva sobre o horizonte de uma problemática cultural que enuncia o que vale, o que importa, o que é significativo em uma cultura determinada" (FABRE, 2011a, p. 78).

À escola cabe atualizar o mapa, modificá-lo de acordo com as transformações da paisagem, das trilhas e das ações que o tempo e a história humana lançarem sobre esse mapa.

\section{Articulações entre o mapa e a bússola}

As metáforas do mapa e da bússola significam uma orientação que não se dá no plano da imperatividade. Trata-se de entregar ao aluno uma bússola e um mapa para que ele trilhe seu próprio caminho, na busca e na construção de si próprio (FABRE, 2011a), com liberdade para escolher qual direção seguir e qual caminho trilhar, apoiando-se na autoridade não para se sujeitar à normatividade que dela emana, mas para se aconselhar, receber sugestões, com base na experiência, na prudência do professor, entendida a última como sabedoria prática, ou seja, como "o conhecimento daquilo que se deve procurar ou evitar" (CÍCERO, 1996, p. 73 74) em determinada situação - o bom senso a serviço de uma boa vontade (COMTESPONVILLE, 1995).

Por certo, essa praxis educacional, como aduzem Dias et al. (2012, p. 201), “extrapola a racionalidade instrumental, pois envolve fatores afetivos, éticos, de desempenho, cognitivos, estéticos e de convivência, entre outros".

Aconselhar, quanto ao educador, requer não autoridade, mas respeitabilidade. Quanto ao aluno, trata-se não de obrigação, mas de faculdade. No tocante às consequências do descumprimento, em sede de conselho, elas recaem sobre o aluno, diferentemente do que ocorre quando se trata de ordem imperativa (BOBBIO, 2006).

Além das funções de localização e de direcionamento, a referência associa-se à função de demarcação, ou seja, ao estabelecimento de limites, de modo a evitar uma ruptura da linha demarcatória conducente à imprudência e à desmesura, no sentido individual e interindividual (FABRE, 2011a, p. 44-45). 
As articulações entre a bússola e o mapa refletem uma condição de transmissão em que a ação do educador, a rigor, não modela a experiência, mas constitui um "ponto de dilatação" dessa experiência (DEWEY, 1968, p. 123 apud FABRE, 2011a, p. 66).

Cabe ao educador, pela experiência, ensinar, imbuído de prudência. Se ele optar por tal caminho, pode se deparar com tal situação, pode haver bifurcações, aclives, declives, retas ou sinuosidades, cabendo ao aluno escolher o caminho a seguir.

Aprender a escolher, não definindo aprioristicamente o que é melhor (REBOUL, 2016). Apesar de haver vários critérios para aferir se uma educação é bem-sucedida, “o principal é que ela seja inacabada, que ela forneça ao sujeito os meios e o desejo de buscá-la, de fazer disso uma autoeducação" (REBOUL, 2016, p. 122).

\section{Considerações finais}

Diante de um mundo problemático, em que há uma pluralidade de valores - alguns inconciliáveis - a impedir o estabelecimento de um sistema de referências seguro, que prevaleça sobre outros sistemas, não se há de seguir um modelo de normatividade educacional injuntivo.

Fabre adota um esquema de legitimação na educação voltado para uma pedagogia do problema, para uma problemática que estrutura uma experiência (FABRE, 2011a, p. 65), topos nuclear no processo de aprendizagem do aluno.

O processo de problematização dessa experiência é articulado, metaforicamente, em dois instrumentos geográficos: a bússola, que abre e polariza o espaço cognitivo em dados, condições, problema e solução; e o mapa, como representação do iter histórico-cultural já percorrido pela humanidade, oferecendo os dados e as condições do problema.

$\mathrm{Na}$ articulação de ambos os instrumentos, não há qualquer imperatividade nesse processo de aprendizagem. Ao aluno cabe trilhar seu próprio caminho, provido de uma bússola e um mapa, auxiliado pelo professor.

Um dos desafios nesse processo está em identificar os instrumentos ou os indutores da problematização que o professor pode utilizar na experiência do aluno, em outras palavras, como pôr em prática essa pedagogia do problema.

Nesse ponto, não há direções únicas nem critérios rígidos a serem construídos pelo professor ou a ele sugeridos. A organização da experiência em um mundo problemático não 
deve ser realizada exclusivamente de modo endógeno ou exógeno, mas em um ambiente de colaboração, enriquecido de dialogias, em detrimento de injuntividades.

\section{REFERÊNCIAS}

BOBBIO, Norberto. O positivismo jurídico: lições de filosofia do direito. São Paulo: Ícone, 2006.

CÍCERO, Marco Túlio. Dos deveres. São Paulo: Martins Fontes: 1996.

COMTE-SPONVILLE, André. La philosophie. Paris: PUF, 2012.

COMTE-SPONVILLE, André. O amor a solidão. 2 ed. São Paulo: Martins Fontes, 2006.

COMTE-SPONVILLE, André. Apresentação da filosofia. São Paulo: Martins Fontes, 2002.

COMTE-SPONVILLE, André. Pequeno tratado das grandes virtudes. São Paulo: Martins Fontes, 1995.

DEWEY, John. L'école et l'enfant. Paris: Fabert, 2004.

DEWEY, John. Expérience et éducation. Paris: Armand Colin, 1968.

DIAS, Adelaide Alves et al. Dimensão da afetividade na constituição da profissionalidade docente. In: PIZZI, Laura Cristina Vieira et al (orgs.). Trabalho docente: tensões e perspectivas. Maceió: EDUFAL, 2012. p. 189-204.

FABRE, Michel. Vivre et éduquer sans absolu. Le Télémaque, nº 50, p. 41-46, 2016.

FABRE, Michel. Quelques implications éducatives de la Problématologie: L'idée de réification chez Michel Meyer, Penser l'éducation, nº 32, p. 30-47, 2012.

FABRE, Michel. Éduquer pour un monde problématique. Paris: PUF, 2011a.

FABRE, Michel. Est-il possible d'éduquer dans un monde problématique? Revue internationale de philosophie, $\mathrm{n}^{\circ} 257$, p- 97-118, $2011 \mathrm{~b}$.

FABRE, Michel. Qu'est-ce que problématiser? Genèses d'un paradigme. Recherches en Education, $n^{\circ}$ 6, p. 22-32, 2009.

FABRE, Michel. Des savoirs scolaires sans problèmes et sans enjeux. La faute à qui? Revue française de pédagogie, $n^{\circ} 161$, p. 69-78, 2007.

FABRE, Michel; MUSQUER, Agnès. Les inducteurs de la problématisation. Les Sciences de l'éducation - Pour l'Ère nouvelle, v. 42, p. 111-129, 2009. 
GALLO, Sílvio. Transversalidade e formação de professores. In: RIVERO, Cléia Maria L.; GALLO, Sílvio (orgs.). A formação de professores na sociedade de conhecimento. Bauru: Edusc, 2004, p. 101-121.

HOUSSAYE, Jean; FABRE, Michel. Peut-on parler d'une problématisation pédagogique?, Recherche \& Formation, n48, p. 107-117, 2005.

LUCKESI, Cipriano Carlos. Filosofia da educação. 3 ed. São Paulo: Cortez, 2011.

MEYER, Michel. La rhétorique. Paris: PUF, 2011.

MEYER, Michel. La problématologie. Paris: PUF, 2010.

REBOUL, Olivier. Philosophie de l’éducation. Paris: PUF, 2016.

ROUSSEAU, Jean-Jacques. Emílio ou da educação. 3 ed. São Paulo; Rio de Janeiro: Difel, 1979.

SILVA, José Divino da. A Educação para a amplitude da experiência. Perspectiva, v. 19, n. 2, p. 331-349, jul./dez. 2001.

\section{SOBRE OS AUTORES}

\section{Ibrahim Camilo Ede Campos}

Doutorando pela Universidade Federal de Alagoas (UFAL), no Programa de Pós-Graduação em Educação. Linha de pesquisa: Processos educativos. Grupo de pesquisa: Filosofia e Educação e Ensino de Filosofia. Professor universitário. E-mail: icec.campos@gmail.com Bolsista FAPEAL/CAPES.

(iD) http://orcid.org/0000-0002-8292-6071

\section{Walter Matias Lima}

Doutor em Educação pela Universidade Estadual de Campinas (UNICAMP). Professor da Universidade Federal de Alagoas (UFAL), no Programa de Pós-Graduação em Educação. Linha de pesquisa: Processos educativos. Grupo de pesquisa: Filosofia e Educação e Ensino de Filosofia. E-mail: waltermatias@gmail.com.

(iD) http://orcid.org/0000-0001-7331-9475 